\title{
Assessment of a rtPCR for the detection of virulent and benign Dichelobacter nodosus, the causative agent of ovine footrot, in Australia
}

\author{
Nickala Best ${ }^{1}$, Lucas Zanandrez ${ }^{2}$, Jacek Gwozdz ${ }^{3}$, Eckard Klien ${ }^{4}$, Nicky Buller ${ }^{4}$, Robert Suter ${ }^{5}$, Grant Rawlin ${ }^{3}$
} and Travis Beddoe ${ }^{1 *}$ (D)

\begin{abstract}
Background: Ovine footrot is a highly contagious bacterial disease of sheep, costing the Australian sheep industry millions of dollars annually. Dichelobacter nodosus, the causative agent of footrot, is a gram-negative anaerobe classed into virulent and benign strains as determined by thermostability of their respective protesases. Current methods for detection of D. nodosus are difficult and time-consuming, however new molecular techniques capable of rapidly detecting and typing $D$. nodosus have been reported.

Results: A competitive real-time PCR (rtPCR) method, based on the ability to detect a 2 nucleotide difference in the aprV2 (virulent) and aprB2 (benign) extracellular protease gene has been tested on Australian samples for determining detection rates, along with clinically relevant cut-off values and performance in comparison to the traditional culturing methods. The rtPCR assay was found to have a specificity of $98.3 \%$ for virulent and $98.7 \%$ for benign detection from samples collected. Sheep with clinical signs of footrot showed a detection rate for virulent strains of $81.1 \%$ and for benign strains of $18.9 \%$. A cut-off value of a Ct of 35 was found to be the most appropriate for use in Victoria for detection of sheep carrying virulent $D$. nodosus.
\end{abstract}

Conclusions: In summary, the rtPCR assay is significantly more capable of detecting D. nodosus than culturing, while there is no significant difference seen in virotyping between the two methods.

Keywords: Australia, Benign, Footrot, Real-time polymerase chain reaction, Sensitivity, Sheep, Specificity, Victoria, Virulent

\section{Background}

Ovine footrot is a highly contagious bacterial disease of sheep, causing lesions in the hoof and lameness [1]. The primary aetiologic agent of ovine footrot is Dichelobacter nodosus, a gram-negative anaerobe [2]. Many strains of $D$. nodosus exist consisting of multiple serogroups that are classified in Australia into virulent or benign based on extracellular protease activity. Infections with benign strains may appear as inflammation of the interdigital skin (interdigital dermatitis), while infections with virulent strains

\footnotetext{
* Correspondence: t.beddoe@latrobe.edu.au

${ }^{1}$ Department of Animal, Plant and Soil Science, Centre for AgriBioscience

(AgriBio), La Trobe University, Bundoora, Melbourne, VIC, Australia

Full list of author information is available at the end of the article
}

may vary from interdigital dermatitis to severe lesions with extensive necrosis and separation of the horn from the soft tissue $[3,4]$. Footrot lesions are graded using a simple scoring system ranging from 0 (clinically healthy) to 5 (severe underrunning of the hard horn of the hoof) $[3,4]$. The severity of lesions produced by virulent strains is reliant on environmental conditions, with temperatures of above $10{ }^{\circ} \mathrm{C}$ and consistent rainfall required for the full expression of virulence factors [5]. Subsequently, when environmental conditions are not optimal, infection with virulent strains may not be apparent clinically or it may present itself as mild infection imitating benign footrot [6]. The virulence potential of the $D$. nodosus strains may be determined by measuring the

(c) The Author(s). 2018 Open Access This article is distributed under the terms of the Creative Commons Attribution 4.0 International License (http://creativecommons.org/licenses/by/4.0/), which permits unrestricted use, distribution, and 
thermostability of serine proteases of isolates using the gelatin gel (gelatinase) test [7]. However, culturebased assays have been reported to have modest diagnostic power [8]. Furthermore, culture-based tests are labour-intensive and requires several weeks for the results to become available [9]. It has been reported that the acidic protease 2 (AprV2) plays a key role in virulence of $D$. nodosus [10]. Virulent strains have the aprV2 gene encoding a thermostable protease. Benign strains have the gene aprB2 encoding a thermolabile protease. The aprV2 and aprB2 alleles vary by a two-base pair substitution. This difference has been exploited in the probe design of a real-time polymerase chain reaction (rtPCR) assay [11]. Using this rtPCR assay, the presence of $D$. nodosus and its virulence can be determined within 1 day. The test is also capable of detecting both benign and virulent in the same clinical sample. There are limited data on the diagnostic performance of the rtPCR in sheep in Europe [12]. The objective of this paper was to evaluate the rtPCR assay with clinical samples collected from sheep in Victoria, Australia, with confirmed or suspected virulent footrot and sheep considered to be free of infection with $D$. nodosus.

\section{Methods}

\section{Sample collection}

The clinical samples were obtained retrospective from Victoria Government Veterinary Diagnostic unit collection. The samples were submitted by Victorian District Veterinary Officers, Animal Health Officers and private veterinary practitioners from the interdigital skin of lame sheep for routine diagnostic testing. Flocks were selected for this study if individual foot scores corresponding to sample labelling from individual sheep were provided, as well as the clinical history of the flock as determined by the submitting persons. Three hundred eighteen sheep from 10 flocks (\#1 to 10) considered free of footrot, 170 sheep from 13 flocks (\#12 to 24) with confirmed and/or suspected virulent footrot and 27 sheep from a closed flock with the history of virulent footrot that was deemed successfully eradicated. Prior to sampling, each sheep was examined and foot lesions scored and recorded. The interdigital skin of the foot with the highest score was sampled using two sterile swabs. One swab was placed into Stuarts Transport Media for culture and the second swab was placed into $800 \mu \mathrm{L}$ of phosphate buffered saline (PBS) $\left(8.1 \mathrm{mM} \mathrm{Na}_{2} \mathrm{HPO}_{4}, 137 \mathrm{mM} \mathrm{NaCl}\right.$, $1.4 \mathrm{mM} \mathrm{KH}_{2} \mathrm{HPO}_{4}$ and $2.6 \mathrm{mM} \mathrm{KCl}$ ) with $20 \mathrm{mM}$ ethylenediaminetetraacetic acid (EDTA), $\mathrm{pH}$ 8.0), for rtPCR. The origin, breed, sex, age, foot score of the sheep sampled and their flock history are presented in Tables 1 and 2. Samples were kept at $4{ }^{\circ} \mathrm{C}$ after collection and sent the following day to AgriBio, 5 Ring Rd., La Trobe,
Bundoora, Victoria, 3083. Samples were submitted for disease investigations pertaining to footrot.

\section{Culturing of $D$. nodosus}

Swabs collected from sheep from flocks 1 to 14 were plated at AgriBio one to 2 days after collection onto 4\% $(w / v)$ agar with $3 \%(w / v)$ ground hoof media (Footrot Reference Laboratory, Department of Agriculture, Perth, Australia) and anaerobically incubated at $37{ }^{\circ} \mathrm{C}$ for 7 days. Plates were examined for $D$. nodosus growth and suspect colonies subcultured and gram stained as described elsewhere [9]. D. nodosus isolate A198 (aprV2) (AC: 6466), virulent control, and isolate C305 (aprB2) (AC: 6465), benign control, were obtained from the Footrot Reference Laboratory and grown concurrently with sample plates. Isolates morphologically consistent with $D$. nodosus were sent on ice to the Footrot Reference Laboratory for gelatinase testing. Swabs collected from sheep from flocks 15 to 24 were sent on ice by overnight courier to the Footrot Reference Laboratory, Perth, Western Australia for culture and gelatinase testing.

\section{DNA extraction}

DNA was extracted from swabs using a commercial extraction kit (MagMAX ${ }^{\mathrm{mi}}-96$ Viral RNA isolation kit, Ambion, Austin, USA) and purification system (Kingfisher-96 magnetic particle handling system, Thermo Fisher Scientific, Finland). Swabs from two positive culture controls were used as positive extraction controls. Swabs collected from sheep from flocks 1 to 14 were subject to DNA extraction on two separate occasions (runs).

\section{aprV2/B2 rtPCR}

Primers, probes and cycling conditions as described by Stauble et al., 2014 were used [11]. A commercial rtPCR kit (AgPath-ID ${ }^{\text {tw }}$ One Step RT-PCR Kit, Ambion, Austin, USA) was used as master mix according to manufacturer's instructions, with final concentrations of $300 \mathrm{nM}$ primers, $100 \mathrm{nM}$ DnAprTM-vMGB, 250 nM DnAprTMbMGB and $5 \mu \mathrm{L}$ of template DNA. Primers and probes were synthesised commercially (Primers and probes, Applied Biosystems, California, USA) Reactions were carried out and analysed (7500 Fast Real-Time PCR System, Life Technologies) with a set threshold of 0.05 . Two DNA extracts derived from sheep from flocks 1 to 14 were assayed by the rtPCR in two separate runs. Singular DNA extracts derived from sheep from flocks 15 to 24 were assayed by the rtPCR in one run.

Positive extraction controls from live cultures of isolate A198 and C305, and purified and isolated genomic DNA from the same culture isolates were used as rtPCR controls in each run. The rtPCR run was considered valid when results obtained in rtPCR controls were 
Table 1 Descriptive characteristics of 11 Australian sheep flocks considered free of virulent footrot were sampled between June '15 and August '15 for evaluation of the specificity of an rtPCR for detection of virulent (aprV2) and benign (aprB2) protease genes of D. nodosus

\begin{tabular}{|c|c|c|c|c|c|c|c|}
\hline Flock ID & $\begin{array}{l}\text { No. animals } \\
\text { sampled }\end{array}$ & $\begin{array}{l}\text { Sampling } \\
\text { date }\end{array}$ & $\begin{array}{l}\text { Flock origin } \\
\text { (shire or city) }\end{array}$ & Breed & Age & Sex & Comments/Flock history \\
\hline 1 & 18 & 02.06 .2015 & City of Broken Hill, NSW & Merino & Lambs & Mixed & Abbatoir line. \\
\hline 2 & 18 & 02.06 .2015 & Blayney Shire, NSW & Mixed & Mixed & Mixed & Abbatoir line. \\
\hline 3 & 19 & 02.06 .2015 & Shire ofArarat, Vic & Mixed & Rams & Male & Abbatoir line. \\
\hline 4 & 18 & 02.06 .2015 & Shire of Ararat, Vic & Merino & Mixed & Female & Abbatoir line. \\
\hline 5 & 19 & 02.06 .2015 & Shire of Ararat, Vic & Merino & Lambs & Mixed & Abbatoir line. \\
\hline 6 & 18 & 02.06 .2015 & City of Wagga Wagga, NSW & Merino & Ewes & Female & Abbatoir line. \\
\hline 7 & 18 & 02.06 .2015 & $\begin{array}{l}\text { Southern Grampians } \\
\text { Shire, Vic }\end{array}$ & Crossbreed & Ewes & Female & Abbatoir line. \\
\hline 8 & 55 & 16.06 .2015 & Yarra Ranges Shire, Vic & Coopworth crosses & Ewes & Female & $\begin{array}{l}\text { Farm has had previous intermittent } \\
\text { lameness, footrot has not been } \\
\text { confirmed as the cause. }\end{array}$ \\
\hline 9 & 81 & 01.07 .2015 & Strathbogie Shire, Vic & Merino & Wethers & Male & $\begin{array}{l}\text { Farm has no history of footrot, but } \\
\text { lameness occasionally observed. } \\
\text { Sheep footbathed late } 2014 \text {. }\end{array}$ \\
\hline 10 & 54 & 17.07.2015 & Wellington Shire, Vic & Merino & Wethers & Male & $\begin{array}{l}\text { Well managed merino stud, no history } \\
\text { of footrot. Wether had strayed into } \\
\text { adjoining properties and had been } \\
\text { cought and shorn } 2 \text { days prior to } \\
\text { sampling. }\end{array}$ \\
\hline $11^{\mathrm{a}}$ & 27 & 05.08.2015 & East Gippsland Shire, Vic & Merino & Ewes & Female & $\begin{array}{l}\text { Virulent footrot first introduced in the } \\
80 \text { 's, treated by footbathing. Second } \\
\text { footrot introduced in 1995; eradicated } \\
\text { by footbathing, antibiotic regime and } \\
\text { culling. A closed flock currently. No } \\
\text { footbathing for } \geq 10 \text { years. }\end{array}$ \\
\hline
\end{tabular}

${ }^{a}$ Flock 11 has been excluded from specificity and sensitivity calculations because of its history

concordant. Results are reported as cycling threshold $(\mathrm{Ct})$ values, the point at which the sample signal exceeds the threshold of 0.05. Samples producing a probe-specific fluorescent signal were defined as being positive. The effect of two cut-off values; $\mathrm{Ct}<40$ and $\mathrm{Ct}<35$, on the rtPCR detection rate and specificity, was assessed.

\section{Data analysis}

Considering the culture/gelatinase method lacks adequate diagnostic accuracy and both the virulent and benign strains of $D$. nodosus may produce subclinical or mild, clinically unapparent infection, detection rates of the aprB2 $\mathrm{rtPCR}$ and aprV2 $\mathrm{rtPCR}$ were calculated using data obtained from 135 sheep with foot lesions and 35 healthy sheep from the 13 flocks with confirmed or suspected virulent footrot. Because of the lack of the gold diagnostic standard, the specificities of the aprB2 $\mathrm{rtPCR}$ and aprV2 rtPCR were calculated using data derived only from the 297 healthy sheep from the 10 flocks considered to be free of footrot. Twenty-one sheep with foot lesions scored 1 and 2 were excluded from the specificity calculations. Both the detection rate of clinically infected animals and specificity of the rtPCR were calculated for cut-offs of Ct of 35 and 40 values respectively, using data obtained in the first rtPCR run. Descriptive statistics were performed with Microsoft Excel 2010, Microsoft Corporation, Redmond, WA. Further analyses including Cohen's kappa statistic (agreement between rtPCR runs, agreement between gelatinase gel test and rtPCR virulence designations), using the Altman scheme where $\leq 0=$ worse than chance alone, $<0.20=$ poor, $0.21-0.40=$ fair, $0.41-0.60=$ moderate, $0.61-0.80=$ good, and $0.81-$ $0.99=$ very good, $1.00=$ perfect and McNemar's test for comparisons of foot lesions vs. rtPCR, culture vs. rPCR and rtPCR run vs. rtPCR run were also performed withGraphPad Prism version 4.01 for Windows, GraphPad Software, La Jolla, CA.

\section{Results}

The rtPCR results in relation to foot scores and culture/ gelatinase test results obtained in 10 flocks considered free of footrot, 13 flocks with confirmed and/or suspected virulent footrot and a closed flock (\#11) with the history of eradicated virulent footrot are presented in Table 3.

For all data, Ct's of 40 and 35 were investigated as suitable cut-off values to interpret positive results. From data collected through the clinically healthy trial, the use of a Ct of 40 showed poor discrimination between healthy and clinically affected sheep in both aprV2 and aprB2 results $(p>0.005$, both, Table 4$)$. When using a $\mathrm{Ct}$ 
Table 2 Descriptive characteristics of 11 Australian sheep flocks considered having virulent footrot were sampled between October '14 and July '15 for evaluation of the specificity of an rtPCR for detection of virulent (aprV2) and benign (aprB2) protease genes of D. nodosus

\begin{tabular}{|c|c|c|c|c|c|c|c|}
\hline Flock ID & $\begin{array}{l}\text { No. animals } \\
\text { sampled }\end{array}$ & $\begin{array}{l}\text { Sampling } \\
\text { date }\end{array}$ & $\begin{array}{l}\text { Flock origin } \\
\text { (shire or city) }\end{array}$ & Breed & Age & Sex & Comments/Flock history \\
\hline 12 & 26 & 27.07.2015 & $\begin{array}{l}\text { Wangaratta Rural } \\
\text { City, Vic }\end{array}$ & Dorper & Rams & Male & $\begin{array}{l}\text { Farm has a history of virulent footrot. } \\
\text { Footbathing and foot pairing done frequently. } \\
\text { Minimal lameness and lesions currently present. } \\
\text { Sheep reviously footbathed in May } 2015 \text {. }\end{array}$ \\
\hline 13 & 10 & 10.07.2015 & $\begin{array}{l}\text { East Gippsland } \\
\text { Shire, Vic }\end{array}$ & Merino Cross & Mixed & Mixed & $\begin{array}{l}\text { Footrot introduced December } 2014 \text { by purchased } \\
\text { rams. Owners observed lameness of about } 1 \text { in } \\
150 \text { animals in March/April } 2015 .\end{array}$ \\
\hline 14 & 36 & 23.06.2015 & Mitchell Shire, Vic & Merino & Rams & Male & $\begin{array}{l}\text { Farm suspected of virulent footrot, samples taken } \\
\text { on a confirmatory visit. }\end{array}$ \\
\hline 15 & 10 & 13.10.2014 & Strathbogie Shire, Vic & Merino & NR & Female & History of footrot and lameness in flock \\
\hline 16 & 10 & 13.10 .2014 & $\begin{array}{l}\text { Greater Shepparton } \\
\text { City, Vic }\end{array}$ & Merino cross & $2.5 \mathrm{y}$ & Female & $\begin{array}{l}\text { A mob of South African Merino X Merino yearling } \\
\text { ewes purchased in Nov-Dec } 2013 \text {. Sheep had been } \\
\text { on agistment. A few sheep lame when they arrived; } \\
\text { footbathed 2-4 weeks before sampling. }\end{array}$ \\
\hline 17 & 10 & 14.10 .2014 & Shire of Newstead, Vic & Merino & Mixed & Female & $\begin{array}{l}\text { Property has a footrot history - previously treated } \\
\text { sucessfully with Footrite }{ }^{\circledR} \text {. This season a recurrance } \\
\text { of lameness, some mobs reached a } 20 \% \text {. }\end{array}$ \\
\hline 18 & 9 & 20.10 .2014 & Indigo Shire, Vic & Dorper & Adult & Female & $\begin{array}{l}\text { Lameness in more than one foot. Lesions } \\
\text { suggestive of benign footrot. }\end{array}$ \\
\hline 19 & 10 & 03.11 .2014 & Shire of Glenelg, Vic & NR & 3.5 years & Female & $\begin{array}{l}\text { Footrot appeared in June; source not determined, } \\
\text { appears to be clinically aggressive; high prevalence } \\
\text { of score } 4 / 5(20 \%+) \text {. These sheep last footbathed } \\
\sim 3 \text { weeks before sampling. }\end{array}$ \\
\hline 20 & 10 & 04.11 .2014 & $\begin{array}{l}\text { Southern Grampians } \\
\text { Shire, Vic }\end{array}$ & NR & 2 years & Female & $\begin{array}{l}\text { Footrot has probably been present for a long time. } \\
\text { Controlled by regular footbathing. Last month have } \\
\text { had } 30 \% \text { of average long term rainfall for this time } \\
\text { of the year. These sheep last footbathed } \sim \text { February } \\
2014\end{array}$ \\
\hline 21 & 10 & 17.11.2014 & Bass Coast Shire, Vic & Droper & Mixed & Mixed & $\begin{array}{l}\text { Many lambs, ewes and some rams reported lame with } \\
\text { lesions very suggestive of footrot. Treated with footbath } \\
\text { (formalin) and antibiotics. The lesions look in a process } \\
\text { of healing but are still obvious (inflammation limited } \\
\text { to interdigital space). }\end{array}$ \\
\hline 22 & 10 & 18.11.2014 & Mitchell Shire, Vic & Merino & NR & NR & Virulent footrot for several years. \\
\hline 23 & 10 & 24.11 .2014 & $\begin{array}{l}\text { Southern Grampians } \\
\text { Shire, Vic }\end{array}$ & NR & Adult & Female & $\begin{array}{l}\text { Footrot appeared in June (source not determined) } \\
\text { with high prevalence of score } 4 / 5(20 \%+) \text {. } \\
\text { Last } 3 \text { months have had } 30 \% \text { of average long } \\
\text { term rainfall for this time of the year. These sheep } \\
\text { last footbathed } \sim 3 \text { weeks earlier. }\end{array}$ \\
\hline 24 & 9 & 01.12 .2014 & $\begin{array}{l}\text { Colac Ottway } \\
\text { Shire, Vic }\end{array}$ & Crossbred & Adult & Female & 10 of 15 seep examined had feet lesions scored $\geq 2$ \\
\hline
\end{tabular}

of 35 and under to indicate positive rtPCR results, detection of footrot using rtPCR differed significantly from using clinical signs alone $(p=0.0014$ for $\operatorname{aprB2}$, and $p=$ 0.019 for aprV2). The agreement between repeated runs at $\mathrm{Ct}$ of 40 for virulent results was good (kappa $=0.731$ ), and perfect when using a Ct of 35 (kappa $=1)$. A similar result is seen for the benign rtPCR results, with a reasonable agreement for a Ct of 40 between repeats (kappa $=0.302)$, and a highly significant agreement when using a Ct of 35 (kappa =1) (Table 4). In the data from clinically affected animals, there was a significant difference between numbers of positive results obtained by the aprV2 rtPCR and aprB2 rtPCR at a cut-off of 40 and
35 respectively, in the clinically affected $(n=135)$ and healthy $(n=35)$ sheep. Using a Ct of 35 resulted in a better agreement between replicates of the same sample (Table 5). Results using a Ct of 35 only will be reported further due to the increased agreement between repeats.

Using 297 animals from historically healthy farms scored 0, specificity was calculated to be $98.3 \%$ for aprV2 detection, and $98.7 \%$ for aprB2 detection when using a Ct of 35 as the cut-off. From these flocks, 318 animals were tested in total, with 21 scored 1-5 (Table 3). One sheep of the 318 from the flocks considered free of footrot yielded growth of $D$. nodosus of undetermined gelatinase profile. This sheep (Flock 2) also produced strong reactions 
Table 3 Clinical scores and results of D. nodosus culture, gelatinase test and rtPCR (aprB2/aprV2 positive, two cut offs, duplicate runs) in 318 sheep from flocks considered to be free of footrot (clinically healthy), 170 sheep from flocks considered having virulent footrot (clinically affected) and 27 sheep from a closed flock (\#11) that apparently eradicated virulent footrot more than 10 years ago. Flocks were sampled from October 2014 to August 2015

\begin{tabular}{|c|c|c|c|c|c|c|c|c|c|c|c|c|c|c|c|c|c|c|c|c|c|}
\hline & \multirow[t]{4}{*}{ Flock ID } & \multirow{4}{*}{$\begin{array}{l}\text { No. sheep } \\
\text { tested }\end{array}$} & \multicolumn{11}{|c|}{ Results } & \multicolumn{4}{|c|}{ aprB2 rtPCR ${ }^{d}$} & \multicolumn{4}{|c|}{ aprV2 rtPCR ${ }^{d}$} \\
\hline & & & \multicolumn{7}{|c|}{ Clinical Score ${ }^{b}$} & \multirow[t]{3}{*}{ Culture $^{c}$} & \multicolumn{3}{|c|}{ Gelatinase test $^{d}$} & \multirow{2}{*}{\multicolumn{2}{|c|}{$\frac{\text { Run } 1}{\text { Cut-off }}$}} & \multirow{2}{*}{\multicolumn{2}{|c|}{$\frac{\text { Run } 2}{\text { Cut-off }}$}} & \multirow{2}{*}{\multicolumn{2}{|c|}{$\frac{\text { Run } 1}{\text { Cut-off }}$}} & \multirow{2}{*}{\multicolumn{2}{|c|}{$\frac{\text { Run } 2}{\text { Cut-off }}$}} \\
\hline & & & \multirow[t]{2}{*}{0} & \multirow[t]{2}{*}{1} & \multirow[t]{2}{*}{2} & \multirow[t]{2}{*}{3} & \multirow[t]{2}{*}{4} & \multirow[t]{2}{*}{5} & \multirow[t]{2}{*}{ Mean } & & \multirow[t]{2}{*}{ Benign } & \multirow[t]{2}{*}{ Virulent } & \multirow[t]{2}{*}{ Undetermined } & & & & & & & & \\
\hline & & & & & & & & & & & & & & 40 & 35 & 40 & 35 & 40 & 35 & 40 & 35 \\
\hline \multirow{10}{*}{$\begin{array}{l}\text { Clinically } \\
\text { healthy }\end{array}$} & 1 & 18 & 18 & - & - & - & - & - & 0 & - & - & - & - & - & - & - & - & - & - & - & - \\
\hline & 2 & 18 & 18 & - & - & - & - & - & 0 & 1 & - & - & 1 & - & - & - & - & 2 & 2 & 2 & 2 \\
\hline & 3 & 19 & 17 & - & 1 & - & 1 & - & 0.1 & - & - & - & - & - & - & 1 & - & - & - & - & - \\
\hline & 4 & 18 & 11 & 1 & 6 & - & - & - & 0.6 & - & - & - & - & - & - & 4 & - & - & - & - & - \\
\hline & 5 & 19 & 19 & - & - & - & - & - & 0 & - & - & - & - & - & - & 2 & - & - & - & - & - \\
\hline & 6 & 18 & 11 & 3 & 1 & 1 & - & 2 & 0.8 & - & - & - & - & - & - & - & - & 5 & 4 & 6 & 4 \\
\hline & 7 & 18 & 16 & 2 & - & - & - & - & 0.1 & - & - & - & - & - & - & - & - & - & - & - & - \\
\hline & 8 & 55 & 55 & - & - & - & - & - & 0 & - & - & - & - & 5 & 1 & 1 & 1 & 3 & 2 & 4 & 2 \\
\hline & 9 & 81 & 81 & - & - & - & - & - & 0 & 2 & 2 & - & - & 5 & 3 & 4 & 3 & 2 & - & 5 & - \\
\hline & 10 & 54 & 51 & 3 & - & - & - & - & 0.1 & - & - & - & - & 8 & - & - & - & 2 & 1 & 2 & 1 \\
\hline Subtotal & & 318 & 297 & 9 & 8 & 1 & 1 & 2 & & 3 & 2 & 0 & 1 & 18 & 4 & $\#$ & 4 & 14 & 9 & 19 & 9 \\
\hline & $11^{\mathrm{a}}$ & 27 & 11 & 16 & - & - & - & - & 0.6 & - & - & - & - & 16 & 10 & 20 & 13 & - & - & - & - \\
\hline Clinically & 12 & 26 & 14 & 12 & - & - & - & - & 0.5 & 7 & - & 5 & 2 & - & - & - & - & 26 & 25 & 26 & 26 \\
\hline & 13 & 10 & 1 & 3 & - & 5 & 1 & - & 2.2 & 4 & 2 & 2 & - & 5 & 3 & 3 & 3 & 9 & 6 & 9 & 6 \\
\hline & 14 & 36 & 20 & 8 & 3 & - & - & 5 & 1.1 & 2 & - & 2 & - & 6 & 5 & 6 & 5 & 17 & 14 & 21 & 13 \\
\hline & 15 & 10 & - & - & 1 & - & 2 & 7 & 4.5 & 2 & - & 2 & - & - & - & ND & ND & 10 & 9 & $N D$ & $N D$ \\
\hline & 16 & 10 & - & - & 4 & 3 & 2 & 1 & 3 & 5 & - & 5 & - & - & - & ND & ND & 10 & 10 & ND & $N D$ \\
\hline & 17 & 10 & - & - & 4 & 2 & 4 & - & 1 & 10 & 4 & 6 & - & 4 & 4 & ND & ND & 6 & 6 & $N D$ & $N D$ \\
\hline & 18 & 9 & - & 9 & - & - & - & - & 4.9 & 3 & - & 3 & - & - & - & ND & ND & 9 & 9 & $N D$ & $N D$ \\
\hline & 19 & 10 & - & - & - & - & 1 & 9 & 2.7 & 3 & - & 3 & - & - & - & ND & ND & 9 & 9 & $N D$ & $N D$ \\
\hline & 20 & 10 & - & - & 4 & 5 & 1 & - & 1.1 & 3 & 2 & 1 & - & 10 & 10 & ND & ND & 10 & 10 & $N D$ & $N D$ \\
\hline & 21 & 10 & - & 9 & 1 & - & - & - & 3.5 & - & - & - & - & 2 & 2 & ND & ND & 2 & 1 & $N D$ & $N D$ \\
\hline & 22 & 10 & - & - & 1 & 5 & 3 & 1 & 3.3 & 6 & 1 & 5 & - & - & - & ND & ND & 10 & 10 & 10 & 10 \\
\hline & 23 & 10 & - & - & - & - & 10 & - & 4 & - & - & - & - & - & - & ND & ND & 10 & 10 & $N D$ & $N D$ \\
\hline & 24 & 9 & - & - & 5 & 2 & 2 & - & 2.6 & - & - & - & - & - & - & ND & ND & 9 & 8 & $N D$ & $N D$ \\
\hline Subtotal & & 170 & 35 & 41 & 23 & 22 & 26 & 23 & & 45 & 9 & 34 & 2 & 27 & 24 & 9 & 8 & 137 & 127 & 66 & 55 \\
\hline
\end{tabular}

a Flock 11 has been excluded from specificity and sensitivity calculations because of its history

${ }^{b}$ Results expressed as a number of sheep in which the highest rated foot was in the particular score

' Results expressed as a number of sheep from which an organism morphologically consistent with $D$. nodosus was isolated

${ }^{d}$ Results expressed as a number of sheep that tested positive

$(\mathrm{Ct} \leq 31)$ in the aprV2 $\mathrm{rtPCR}$ in both runs. Two other sheep (Flock 9) tested positive for the benign strain of $D$. nodosus by culture/gelatinase test and also by the aprB2 rtPCR in both runs $(\mathrm{Ct} \leq 33.74)$. One of these two sheep gave also a weak reaction (Ct 38.39) in the aprV2 rtPCR in one run. All three sheep that yielded growth of $D$. nodosus and tested positive by the aprV2 rtPCR and/or aprB2 $\mathrm{rtPCR}$ were clinically healthy (Table 3).

From the 170 animals clinically affected or suspected, 135 were scored 1 or above and considered clinically affected, while 35 were scored 0 . The rtPCR produced positive virulent results in 112 of the 135 clinically affected sheep, giving a detection rate of $83 \%$ when using a $\mathrm{Ct}$ of 35 , or $81.1 \%$ overall when using all 170 animals (Table 3 ).

In comparison, 45 animals from the 170 in the affected group had $D$. nodosus isolates successfully obtained and 43 had the gelatinase test performed (Table 6). There was a significant difference between the two methods capabilities to detect virulent $D$. nodosus $(p<0.0001)$. Comparing the gelatin gel designation of virulence to 
Table 4 Results of duplicate runs at cut offs Ct 40 and 35 for aprV2 and aprB2 rtPCR in 297 clinically healthy sheep and 21 sheep with foot lesions from 10 flocks considered free of footrot

\begin{tabular}{|c|c|c|c|c|c|c|c|c|}
\hline \multirow[t]{2}{*}{ Foot lesion } & \multicolumn{4}{|l|}{ Cut off 40} & \multicolumn{4}{|l|}{ Cut off 35} \\
\hline & Run $1+$ ve & Run 1 -ve & Run $2+$ ve & Run 2 -ve & Run $1+$ ve & Run 1 -ve & Run $2+$ ve & Run 2 -ve \\
\hline \multicolumn{9}{|l|}{$\overline{a p r B 2}$} \\
\hline Positive & 0 & 21 & 2 & 19 & 0 & 21 & 0 & 21 \\
\hline Negative & 18 & 279 & 10 & 287 & 4 & 293 & 4 & 293 \\
\hline Specificity & & $93.90 \%$ & & $96.60 \%$ & & $98.70 \%$ & & $98.70 \%$ \\
\hline McNemars two tailed $p$ value & & 0.7488 & & 0.1374 & & 0.0014 & & 0.0014 \\
\hline \multicolumn{9}{|l|}{ aprB2 cut off agreement } \\
\hline Run $2+$ ve & 5 & 7 & & & 4 & 0 & & \\
\hline Run 2 -ve & 13 & 293 & & & 0 & 314 & & \\
\hline Kappa & 0.302 & "fair" & & & 1 & "perfect" & & \\
\hline \multicolumn{9}{|l|}{ aprv2 } \\
\hline Positive & 4 & 17 & 4 & 17 & 4 & 17 & 4 & 17 \\
\hline Negative & 10 & 287 & 15 & 282 & 5 & 292 & 5 & 292 \\
\hline Specificity & & $96.60 \%$ & & $94.90 \%$ & & $98.30 \%$ & & $98.30 \%$ \\
\hline McNemars two tailed $p$ value & & 0.2482 & & 0.8597 & & 0.019 & & 0.019 \\
\hline \multicolumn{9}{|l|}{ aprV2 cut off agreement } \\
\hline Run $2+$ ve & 12 & 7 & & & 9 & 0 & & \\
\hline Run 2 -ve & 2 & 297 & & & 0 & 309 & & \\
\hline Kappa & 0.713 & "good" & & & 1 & "perfect" & & \\
\hline
\end{tabular}

Specificity is shown along with $p$-value for McNemar's test for independence between lesion score and rtPCR result, and kappa statistic for agreement between rtPCR runs

Table 5 Results from two cut offs of Ct 40 and 35 from the aprB2 rtPCR and aprV2 rtPCR obtained from two runs, in 72 sheep randomly sampled from 3 flocks considered having virulent footrot

\begin{tabular}{|c|c|c|c|c|c|c|c|c|}
\hline \multirow[t]{2}{*}{ Foot lesion } & \multicolumn{4}{|l|}{ Cut off 40} & \multicolumn{4}{|l|}{ Cut off 35} \\
\hline & Run $1+$ ve & Run 1 -ve & Run $2+$ ve & Run 2 -ve & Run $1+$ ve & Run 1 -ve & Run $2+$ ve & Run 2 -ve \\
\hline \multicolumn{9}{|l|}{ aprB2 } \\
\hline Positive & 9 & 28 & 8 & 29 & 7 & 30 & 7 & 30 \\
\hline Negative & 2 & 33 & 1 & 34 & 1 & 34 & 1 & 34 \\
\hline Overall \% positive & & $15.30 \%$ & & $12.50 \%$ & & $11.10 \%$ & & $11.10 \%$ \\
\hline McNemars two tailed $p$ value & & $<0.0001$ & & $<0.0001$ & & $<0.0001$ & & $<0.0001$ \\
\hline \multicolumn{9}{|l|}{ aprB2 cut off agreement } \\
\hline Run $2+$ ve & 8 & 1 & & & 8 & 0 & & \\
\hline Run 2 -ve & 3 & 60 & & & 0 & 64 & & \\
\hline Kappa & 0.768 & "good" & & & 1 & "perfect" & & \\
\hline \multicolumn{9}{|l|}{ aprV2 } \\
\hline Positive & 33 & 4 & 33 & 4 & 30 & 7 & 29 & 8 \\
\hline Negative & 19 & 16 & 23 & 12 & 15 & 20 & 16 & 19 \\
\hline Overall \% positive & & $72.20 \%$ & & $77.80 \%$ & & $62.50 \%$ & & $62.50 \%$ \\
\hline McNemars two tailed $p$ value & & 0.0035 & & 0.0005 & & 0.1356 & & 0.153 \\
\hline \multicolumn{9}{|l|}{ aprV2 cut off agreement } \\
\hline Run $2+$ ve & 51 & 5 & & & 44 & 1 & & \\
\hline Run 2 -ve & 1 & 15 & & & 1 & 26 & & \\
\hline Kappa & 0.779 & "good" & & & 0.941 & "very good" & & \\
\hline
\end{tabular}

The $p$-value for McNemar's test for independence between lesion score and rtPCR result is shown along with kappa statistic for agreement between rtPCR runs 
Table 6 Gelatinase gel test and rtPCR results for 45 individual samples within the clinically affected data set that successfully had $D$. nodosus isolated, where $S$ is thermostable (virulent) and $U$ is thermolabile (benign)

\begin{tabular}{llll}
\hline Flock ID & Score $^{\text {a }}$ & Gelatinase gel test & rtPCR \\
\hline 12 & 1 & $\mathrm{~S}$ & aprV2 \\
& 1 & $\mathrm{~S}$ & aprV2 \\
& 0 & $\mathrm{~S}$ & aprV2
\end{tabular}

$\begin{array}{lll}0 & S & \text { aprV2 } \\ 0 & \text { NA } & \text { aprV2 } \\ 0 & S & \text { aprV2 } \\ 0 & \text { NA } & \text { aprV2 } \\ 0 & S & \text { aprV2 }\end{array}$

$3 \mathrm{~B}$
$3 \mathrm{C}$

14 aprv2

aprv2 and aprB2

aprV2 and aprB2

aprv2

aprv2

aprv2

aprV2 and aprB2

aprv2

aprv2

aprv2

aprv2

aprv2

aprv2

aprV2

aprv2

aprv2

aprB2

aprB2

aprB2

aprB2

aprv2

aprv2

aprv2

aprv2

aprv2

aprv2

aprv2

aprv2

aprv2

aprv2

aprv2 and aprB2

aprv2 and aprB2

aprv2 and aprB2

aprv2

aprv2

aprv2
Table 6 Gelatinase gel test and rtPCR results for 45 individual samples within the clinically affected data set that successfully had $D$. nodosus isolated, where $S$ is thermostable (virulent) and $\mathrm{U}$ is thermolabile (benign) (Continued)

\begin{tabular}{llll}
\hline Flock ID & Score $^{a}$ & Gelatinase gel test & rtPCR \\
\hline $3 \mathrm{~A}$ & $\mathrm{~S}$ & aprV2 \\
3 & $\mathrm{~S}$ & aprV2 \\
4 & $\mathrm{~S}$ & aprV2 \\
\hline
\end{tabular}

a Foot scores are according to Stewart et al., 1983 [4]. An additional file describes the foot scoring in more detail (see Additional file 1)

the rtPCR results, there is no significant difference between the two tests when using 37 of the isolates (McNemars Test, $p=0.479$ ). Samples that tested positive for aprV2 and aprB2 via rtPCR and had D. nodosus successfully isolated were excluded from the above calculation as no sample had more than one isolate obtained. None of the 135 clinically affected sheep and 35 clinically healthy sheep tested negative by the aprV2 rtPCR but positive for the virulent strain of $D$. nodosus by the culture/gelatinase test. The agreement between results produced by the aprV2 rtPCR and that obtained by the culture/gelatinase test ranged from fair (Kappa $=0.2-$ 0.222 ) to poor (kappa $=0.082-0.158$ ) (Table 7). In total, when the affected flock samples were cultured, an overall detection rate of $25 \%$ was obtained (Table 7 ).

There was a significant difference $(p \leq 0.0015)$ between numbers of animals tested positive for the virulent strain of $D$. nodosus by the aprV2 rtPCR and culture/gelatinase test among the 35 clinically healthy sheep. In this group, the aprV2 rtPCR gave positive results in 15 (42.9\%) and $16(45.7 \%)$ of clinically healthy animals at a $\mathrm{Ct}$ of 35 cut-off value in run 1 and run 2, respectively, whereas the gelatinase test gave positive results in 3 of the healthy animals (Table 7).

The same method was applied to aprB2 rtPCR positive samples, resulting in a detection rate of $18.9 \%$, with 23 of 135 clinically affected animals (17\%) positive for aprB2 via rtPCR. Using culturing and the gelatin gel test, $9(6.7 \%)$ of the 135 clinically affected animals tested positive for benign $D$. nodosus. Again, there was a significant difference between the two methods capabilities to detect benign $D$. nodosus $(p=0.0022)$. Two of the 135 clinically affected sheep tested positive for the benign strain of $D$. nodosus by the culture/gelatinase test but negative by the aprB2 rtPCR. The agreement between results produced by the aprB2 $\mathrm{rtPCR}$ and that obtained by the culture/gelatinase test ranged from fair (Kappa = $0.336-0.378$ ) to poor (kappa $=0-0.163$ ) (Table 8).

Among the 35 clinically healthy sheep, there was no significant difference $(p=1)$ between numbers of animal's positive for the benign strain of $D$. nodosus by the aprB2 rtPCR and culture/gelatinase test. In this group, the aprB2 $\mathrm{rtPCR}$ at a $\mathrm{Ct}$ of 35 gave a positive reaction in 


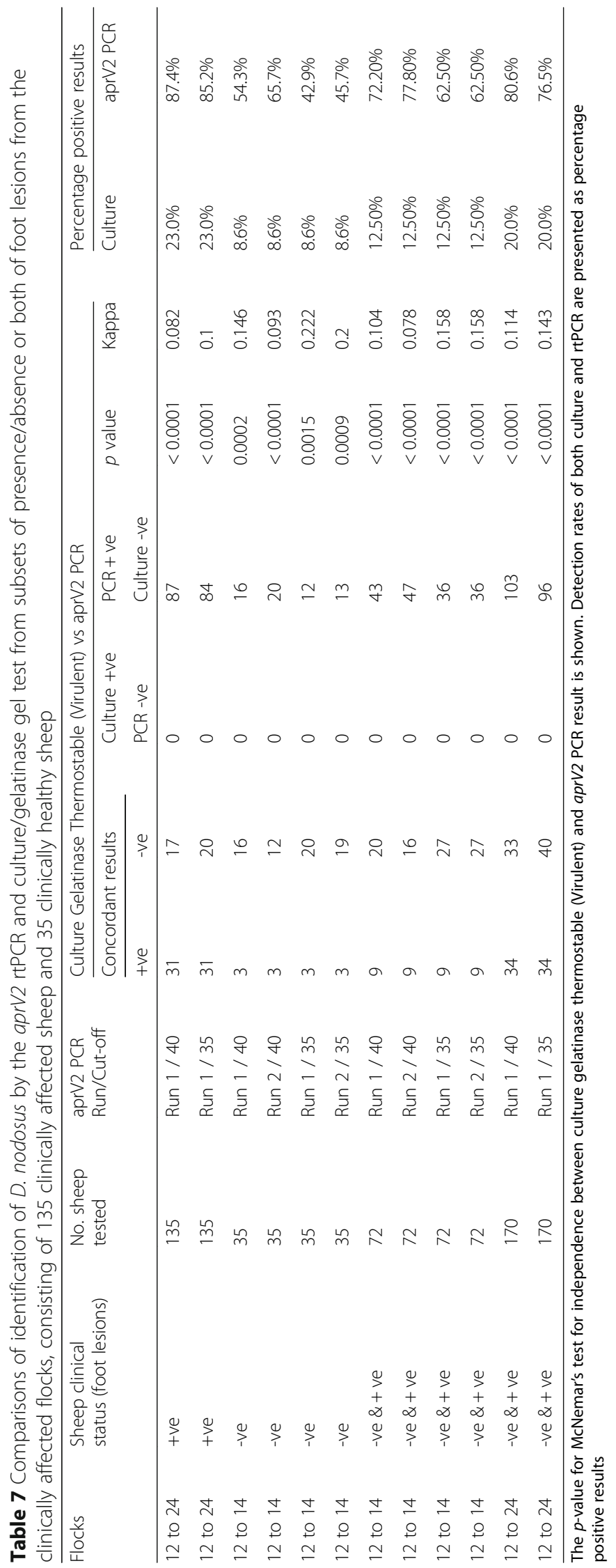




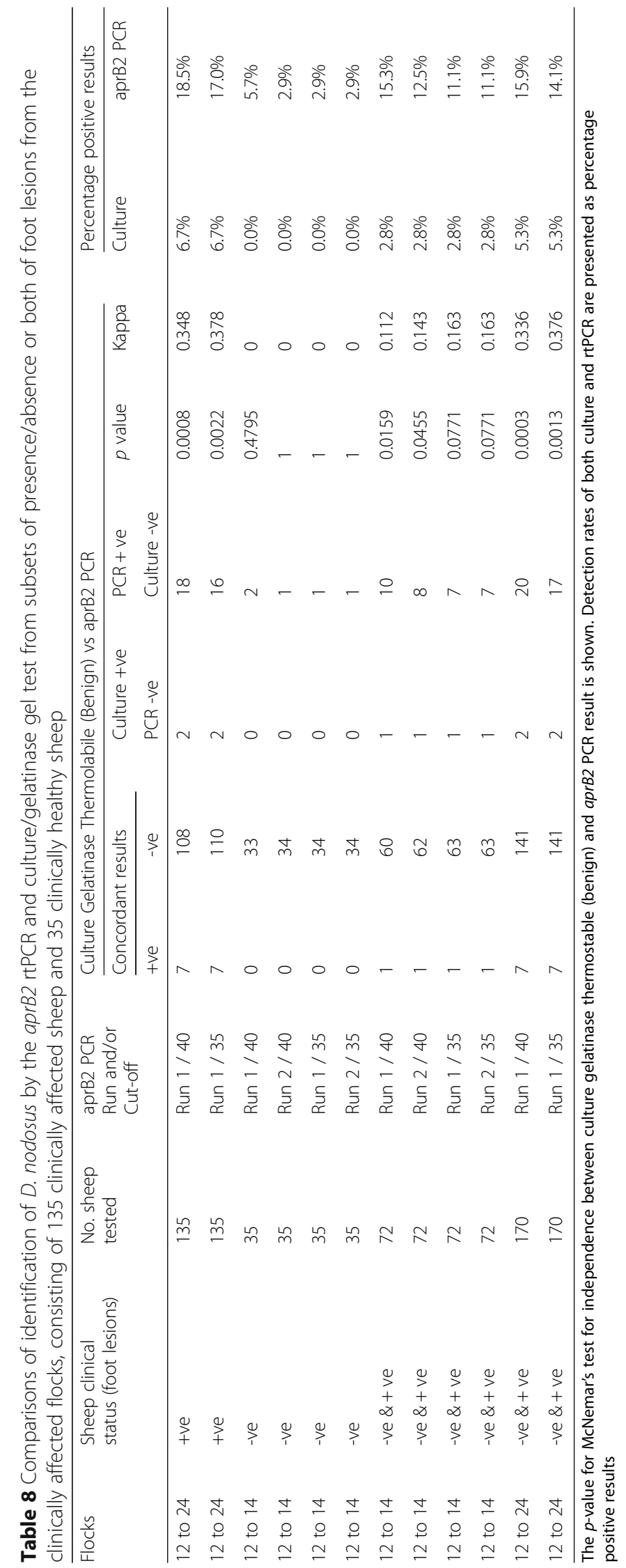


1 (2.9\%) animal. None of the 35 clinically healthy sheep tested positive for the benign strain of $D$. nodosus by the culture/gelatinase test.

\section{Discussion}

New molecular techniques capable of rapidly detecting and typing $D$. nodosus are required for improved diagnostics in Australia. A rtPCR method, capable of detecting and discrimination virulent $D$. nodosus strains, has been developed under European conditions. This rtPCR was assessed on Australian samples for detection rates, along with clinically relevant cut-off values. Ct values of 40 and 35 for positive identification cut off were investigated with regards to repeatability between runs, with signals above $\mathrm{Ct} 35$ showing more discrepancies than those below 35. This is common in rtPCR assays, often with results past the Ct of 35 commonly seen as outliers [13]. In addition to higher specificities and more significant results at a Ct of 35 for positive samples ( $a p r V 2, p=0.019$, aprB2, $p=0.002$, McNemar's two-tailed $p$-value), no animal scored 1 or above returned a positive result above a $\mathrm{Ct}$ of 35, supporting the use of a cut-off set at 35 in diagnosing animals with some form of the disease. Interestingly, 6 animals that are clinically negative were aprV2 positive after lowering the cut-off. This could suggest that these animals be monitored for clinical signs of footrot when favourable environmental conditions occur. They may potentially be asymptomatic carriers depending on circumstance, with the ability to re-infect the flock $[14,15]$.

The diagnostic power of rtPCR was assessed using the current clinical scoring system to judge if an animal was diseased, or free from disease, as this is the currently accepted method of diagnosis in Victoria. The detection of $D$. nodosus on 3 animals within the healthy population, by both rtPCR and culturing, suggests the presence of infection but not the disease [15]. As the population used for the detection of $D$. nodosus on clinically affected animals was deliberately chosen for clinical virulence, a low detection rate for benign $D$. nodosus was anticipated. From the animals that had the aprB2 gene detected in the $\mathrm{rtPCR}, 81 \%$ were in association with a co-infection, where aprV2 was also detected. As the virulent form of footrot is the clinical disease of interest, no additional investigation into a purely benign population was conducted. The reported overall detection rate for $\operatorname{aprV2}$ at a $\mathrm{Ct}$ of 35 is conservative, with an increase being seen when using a $\mathrm{Ct}$ of 40 (89.7\%), and also when only using animals scored $3-5$, which are traditionally considered virulent [9]. However, as the population used had confirmed or suspected of virulent footrot, the full range of scores were used to indicate the presence of disease. As $D$. nodosus is found in the sheep hoof environment and its presence does not always result in disease [16], it was expected that a number of the clinically negative sheep, throughout the whole data set, would return a positive result due to the nature of the sheep hoof and its environment. Further research monitoring the development of disease in association with environment on these animals may provide insights into the usefulness of $D$. nodosus detection prior to lesion formation, and therefore have practical management applications.

Time taken to receive a result using the rtPCR was typically within 1 day of sample collection or receipt. This is in comparison to the average of 2 to 4 weeks taken for a result when using the culturing method, while the rtPCR also provided better detection of $D$. nodosus from the samples collected. The advantage this provides would allow for a timelier confirmation of the presence of $D$. nodosus, confirming the clinical symptom is in association with the presence of bacteria. The gelatinase test relies on the phenotypic expression of proteases and the associated thermostability of those produced, and the culturing of $D$. nodosus is difficult and requires specialist skills and media. There are also inherent disadvantages to using this method, including the chance of missing strains of $D$. nodosus in the sample, and in the instance of this study, no facility was available in Victoria for the virotyping of isolates, so transport was required. This increases the likelihood of damage to the bacteria in transport and may affect the expression of proteases, the amount made or the ability to reliably have thermostability measured [17]. This may have been the cause of the disagreements from one sample in the clinically healthy data, and two from the clinically affected data. Despite this, there was no significant difference between the two tests when it came to identifying the virulence of the isolates. Instances of results where the rtPCR has detected both virulent and benign protease from a sample, yet culturing missed one or the other strain, are shown in 6 cases from the clinically affected data.

There are many challenges with footrot and the assessment of new diagnostic testing methods due to complex interplay between $D$. nodosus, environment and the host which may result in clinical signs of disease [18]. The method of assessment here reflects the way implementation and sample collection would occur in the field, and so the analysis is appropriate for Victoria's methods of disease investigation. The most prominent difficulty is that the development of lesions is required for a visual diagnosis, to which rtPCR detection rate has been evaluated against. Factors like sheep breed, management, weather, and timing of inspection may all contribute to the lack of lesion, yet $D$. nodosus may still be present and found by the rtPCR. This would contribute to reduced specificity due to being rtPCR positive for $D$. nodosus, yet lesion negative, or lesions that are healing and not indicative of the infecting strain $[19,20]$. 


\section{Conclusions}

The improved speed and detection of virulent $D$. nodosus by this rtPCR assay could lead to a change of animal husbandry practices if the focus were to shift from clinical disease to the detection of virulent $D$. nodosus, indicating infection [15]. The ability to pool samples for this type of rtPCR has also been demonstrated [21, 22], an advantage in time and cost over culturing. Testing of this nature is also capable of detecting and quantifying the bacteria associated with the clinical disease, providing the basis to measure the success of various management practices for both treatment and prevention of footrot [23].

\section{Additional file}

Additional file 1: Definition of footrot scoring system. (DOCX $12 \mathrm{~kb}$ )

\section{Abbreviations}

EDTA: Ethylenediaminetetraacetic acid; rtPCR: Competitive real-time PCR

\section{Acknowledgements}

We would like to thank the district veterinary officers, animal health officers, and the farmers for their time, effort and sheep. Additional thanks to the DEDJTR molecular and bacteriology diagnostic teams, specimen reception and the WA Animal Health Laboratories. We thank the three anonymous reviewers whose comments/suggestions helped improve and clarify this manuscript.

\section{Funding}

The Victorian Sheep and Goat Compensation fund.

\section{Availability of data and materials}

The information supporting the conclusions of this article is included in the article.

\section{Authors' contributions}

$N B, L Z$ was responsible for the experimental work, data analysis, and writing of the manuscript. JG contributed to the writing of the manuscript and reviewed the drafts. EK and NB provided knowledge, training and culturing of $D$. nodosus. GR and TB coordinated the project, contributed to the experimental design, and reviewed the drafts. All authors read and approved the final version of the manuscript.

\section{Ethics approval and consent to participate}

Not applicable.

\section{Consent for publication}

Not applicable.

\section{Competing interests}

The authors declare that they have no competing interests.

\section{Publisher's Note}

Springer Nature remains neutral with regard to jurisdictional claims in published maps and institutional affiliations.

\footnotetext{
Author details

${ }^{1}$ Department of Animal, Plant and Soil Science, Centre for AgriBioscience (AgriBio), La Trobe University, Bundoora, Melbourne, VIC, Australia. ${ }^{2}$ Federal University of Minas Gerais, Belo Horizonte, Minas Gerais, Brazil. ${ }^{3}$ Department of Economic Development, Jobs, Transport and Resources Centre for AgriBioscience (AgriBio), Victorian Government, Bundoora, Melbourne, VIC, Australia. ${ }^{4}$ DAFWA Diagnostics and Laboratory Services, Biosecurity and Regulation, Department of Agriculture and Food, South Perth, Western Australia. ${ }^{5}$ Agriculture Services and Biosecurity Operations, Department of Economic Development, Jobs, Transport and Resources, Attwood, Victoria, Australia.
}

Received: 11 December 2017 Accepted: 16 August 2018

Published online: 29 August 2018

\section{References}

1. Egerton JR, Roberts DS, Parsonson IM. The aetiology and pathogenesis of ovine foot-rot. I A histological study of the bacterial invasion. J Comp Pathol. 1969;79(2):207-15.

2. Bennett G, Hickford J, Sedcole R, Zhou H. Dichelobacter nodosus, fusobacterium necrophorum and the epidemiology of footrot. Anaerobe. 2009;15(4):173-6.

3. Egerton JR, Roberts DS. Vaccination against ovine foot-rot. J Comp Pathol. 1971;81(2):179-85.

4. Stewart DJ, Clark BL, Peterson JE, Griffiths DA, Smith EF, O'Donnell IJ. Effect of pilus dose and type of Freund's adjuvant on the antibody and protective responses of vaccinated sheep to Bacteroides nodosus. Res Vet Sci. 1983; 35(2):130-7

5. Graham NP, Egerton JR. Pathogenesis of ovine foot-rot: the role of some environmental factors. Aust Vet J. 1968;44(5):235-40.

6. Liu D, Roycroft C, Samuel J, Webber J. A retrospective study of clinical and laboratory characteristics of ovine footrot. Vet Microbiol. 1994;42(4):373-81.

7. Liu D, Roycroft C, Samuel J, Webber J. Relationship between clinical manifestations of footrot and specific DNA products of Dichelobacter nodosus amplified through PCR. Res Vet Sci. 1995;59(2):102-5.

8. Liu D, Webber J. A polymerase chain reaction assay for improved determination of virulence of Dichelobacter nodosus, the specific causative pathogen for ovine footrot. Vet Microbiol. 1995:43(2-3):197-207.

9. Buller NB, Eamens G. Ovine Footrot - Australian and New Zealand Standard Diagnositic Procedure. Australian Goverment; 2014. http://www.agriculture. gov.au/SiteCollectionDocuments/animal/ahl/ANZSDP-Ovine-footrot.pdf.

10. Riffkin MC, Wang LF, Kortt AA, Stewart DJ. A single amino-acid change between the antigenically different extracellular serine proteases V2 and B2 from Dichelobacter nodosus. Gene. 1995;167(1-2):279-83.

11. Stauble A, Steiner A, Frey J, Kuhnert P. Simultaneous detection and discrimination of virulent and benign Dichelobacter nodosus in sheep of flocks affected by foot rot and in clinically healthy flocks by competitive real-time PCR. J Clin Microbiol. 2014;52(4):1228-31.

12. Stauble A, Steiner A, Normand L, Kuhnert P, Frey J. Molecular genetic analysis of Dichelobacter nodosus proteases AprV2/B2, AprV5/B5 and BprV/ B in clinical material from European sheep flocks. Vet Microbiol. 2014;168(1): 177-84.

13. Goni R, Garcia P, Foissac S. The qPCR data statistical analysis. Integromics SL, Integromics White Paper; 2009. p. 1-9.

14. Depiazzi LJ, Roberts WD, Hawkins CD, Palmer MA, Pitman DR, McQuade NC, Jelinek PD, Devereaux DJ, Rippon RJ. Severity and persistence of footrot in merino sheep experimentally infected with a protease thermostable strain of Dichelobacter nodosus at five sites. Aust Vet J. 1998;76(1):32-8.

15. Locher I, Greber D, Holdener K, Luchinger R, Haerdi-Landerer C, Schuepbach-Regula G, Frey J, Steiner A. Longitudinal Dichelobacter nodosus status in 9 sheep flocks free from clinical footrot. Small Rumin Res. 2015;132:128-132.

16. Green LE, George TR. Assessment of current knowledge of footrot in sheep with particular reference to Dichelobacter nodosus and implications for elimination or control strategies for sheep in Great Britain. Vet J. 2008;175(2):173-80.

17. Liu D, Yong WK. Improved laboratory diagnosis of ovine footrot: an update. Vet J. 1997:153(1):99-105.

18. McPherson AS, Dhungyel OP, Whittington RJ. Evaluation of genotypic and phenotypic protease virulence tests for Dichelobacter nodosus infection in sheep. J Clin Microbiol. 2017;55(5):1313-26.

19. Witcomb LA, Green LE, Calvo-Bado LA, Russell CL, Smith EM, GrogonoThomas R, Wellington EM. First study of pathogen load and localisation of ovine footrot using fluorescence in situ hybridisation (FISH). Vet Microbiol. 2015;176(3-4):321-7.

20. Witcomb LA, Green LE, Kaler J, UI-Hassan A, Calvo-Bado LA, Medley GF, Grogono-Thomas R, Wellington EM. A longitudinal study of the role of Dichelobacter nodosus and fusobacterium necrophorum load in initiation and severity of footrot in sheep. Prev Vet Med. 2014;115(1-2):48-55.

21. Frosth $S$, Konig U, Nyman AK, Aspan A. Sample pooling for real-time PCR detection and virulence determination of the footrot pathogen Dichelobacter nodosus. Vet Res Commun. 2017;41(3):189-93. 
22. Greber D, Locher I, Kuhnert P, Butty MA, Holdener K, Frey J, SchupbachRegula G, Steiner A. Pooling of interdigital swab samples for PCR detection of virulent Dichelobacter nodosus. J Vet Diagn Investig. 2018;30(2):205-10.

23. Greber D, Bearth G, Luchinger R, Schuepbach-Regula G, Steiner A.

Elimination of virulent strains (aprV2) of Dichelobacter nodosus from feet of 28 Swiss sheep flocks: a proof of concept study. Vet J. 2016;216:25-32.

Ready to submit your research? Choose BMC and benefit from:

- fast, convenient online submission

- thorough peer review by experienced researchers in your field

- rapid publication on acceptance

- support for research data, including large and complex data types

- gold Open Access which fosters wider collaboration and increased citations

- maximum visibility for your research: over $100 \mathrm{M}$ website views per year

At $\mathrm{BMC}$, research is always in progress.

Learn more biomedcentral.com/submissions 